\title{
Granular Cell Tumor of the Tongue: 2 Cases Report and Review of the Literature
}

\section{Caixeirinho $\mathrm{P}^{*_{1}}$, Machado $\mathrm{MDC}^{1}$ and Fernandes $\mathrm{AM}^{2}$}

${ }^{1}$ Department of Stomatology, Centro Hospitalar de Lisboa Central, Lisbon, Portugal

${ }^{2}$ Department of Pediatric Stomatology, Centro Hospitalar de Lisboa Central, Lisbon, Portugal

*Corresponding author: Caixeirinho P, Resident, Department of Stomatology, Centro Hospitalar de Lisboa Central, Lisbon, Portugal, Tel: +351965459739, E-mail: p_caixeirinho@hotmail.com

Citation: Caixeirinho P, Machado MDC, Fernandes AM (2019) Granular Cell Tumor of the Tongue: 2 Cases Report and Review of the Literature. J Case Rep Stud 7(1): 105. doi: 10.15744/2348-9820.7.105

Received Date: November 12, 2018 Accepted Date: February 25, 2019 Published Date: February 27, 2019

\begin{abstract}
Granular cell tumor, also known as Abrikossoff tumor, is a rare lesion that arises from the nervous system. Most of these tumors are benign and only 1-2\% are malignant. Although they can be found in any part of the human body, 45-65\% appears in the head and neck region, mainly in the oral cavity. Here, we report 2 cases of granular cell tumor of the tongue, diagnosed by excisional biopsy. Until the present moment, both patients remain with no recurrence.
\end{abstract}

Keywords: Granular Cell Tumor; Tongue; Intraoral Tumor

\section{Introduction}

Granular cell tumor (GCT) was first described by Abrikossoff in 1926 [1,2]. The etiology was controversial, but it has now been determined that GCT has a neuroectodermal origin [1,3-5]. GCTs areun common soft tissue tumors, with a prevalence ranging from $0.019 \%$ to $0.03 \%$ of all tumors $[4,6,7]$.

According to the most recent World Health Organization (WHO) system for classification of soft tissue tumors, which was published in 2013, GCTs are included in the group of nerve sheath tumors [8]. Soft tissue tumors can be divided, according to biological behaviour, into benign tumors, intermediate tumors and malignant tumors [8,9]. GCTs are benign tumors and their malignant version, an extremely rare entity, is the malignant granular cell tumor [8].

The intermediate tumors have two distinct subtypes: the 'locally aggressive', with the potential for local invasion, and the 'rarely metastasizing, with the potential for distant metastasis. GCTs are benign tumors [8,9]. They are more common in women, between the fourth and sixth decade, and have higher incidence in Black populations GCTs usually affect the skin, oral cavity and remaining gastrointestinal tract [2,4-7]. Most GCTs appear as a slow growth single tumor [1-6,10].

\section{Case 1}

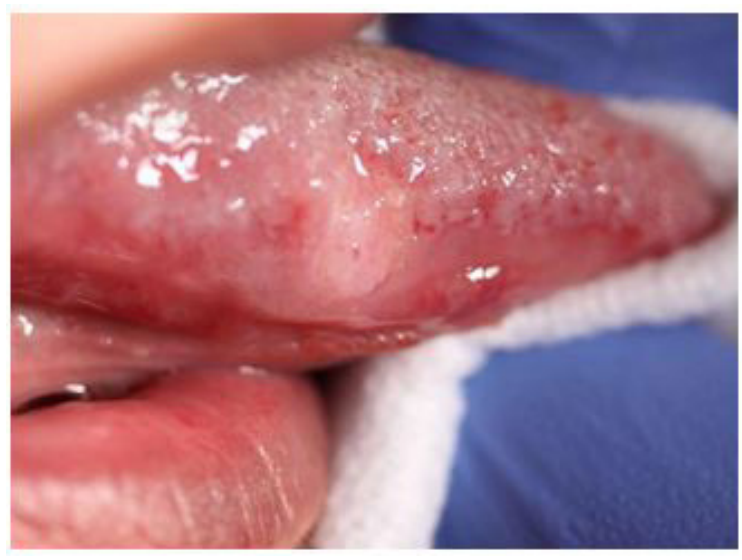

Figure 1: Single, well-delimited noduleis located in the middle third of the right border of the tongue 
A healthy 51-year-old Caucasian 30 woman, with no smoking or drinking habits, was referred to our Stomatology Department with a seven-month history of a painless nodule located in the tongue. An intra-oral examination identified a whitish, painless, elastic nodule on the right border of the tongue, measuring approximately $1 \mathrm{~cm}$ in diameter. No ulcerations were seen (Figure 1 ).

Excisional biopsy was performed. Histopathologic analysis revealed a neoplastic lesion with pseudo epitheliomatous hyperplasia, large and polygonal cells with eosinophilic and granular cytoplasm (Figure 2 and 3) and S100 protein positivity (Figure 4). The diagnosis was GCT with tumor free-margins. Ten months after excision, the patient still has no recurrence.

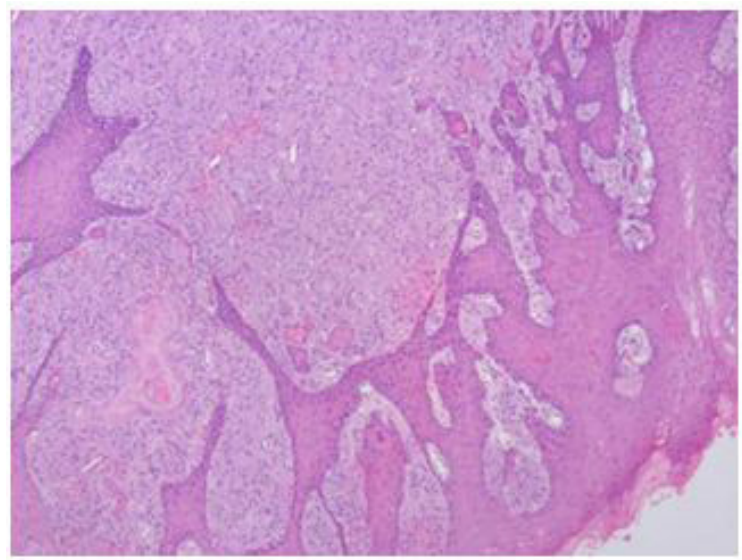

Figure 2: Pseudoepitheliomatous hyperplasia is overlying the granular cell tumor. Hematoxylin and eosin stain. Magnification 40x

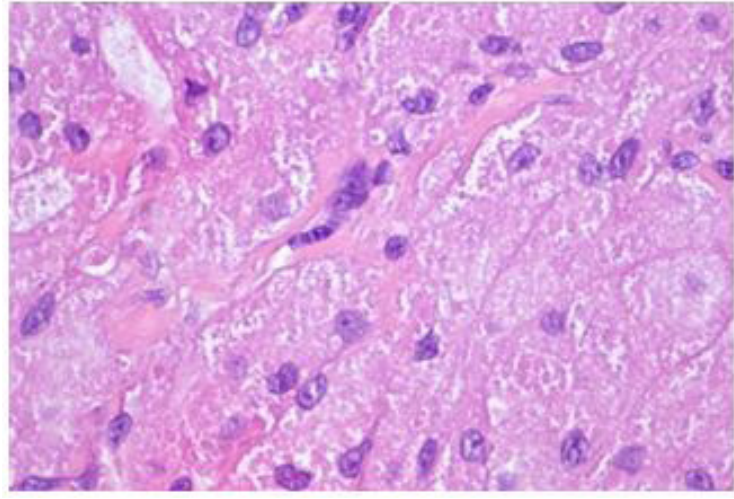

Figure 3: Large and polygonal cells, with eosinophilic cytoplasm and regular granules. No atypia and no mitosis. Hematoxylin and eosin stain. Magnification 400x

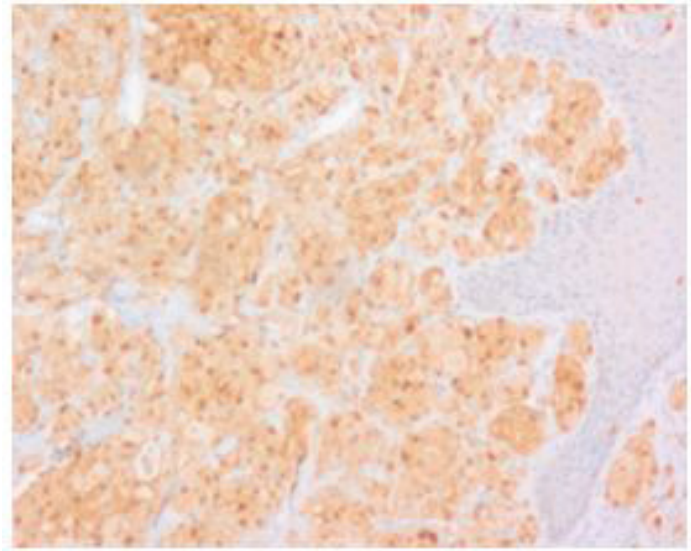

Figure 4: Immunohistochemical positivity (nuclear and cytoplasmatic) with S-100 stain. Magnification 100x

\section{Case 2}

A healthy 60-year-old male patient was referred to our department with anasymptomatic tongue lump known for two years. The patient related this lesion to denture induced trauma. On oral examination, a solitary, reddish, non-ulcerated, $1 \mathrm{~cm}$ sized lesion was seen in theleft dorsal surface of the tongue. Excisional biopsy was consistent with GCT (Figure 5 and 6), even though with positive surgical margins. The patient refused further surgery. 1 year after excision, there is no visible tumor growth. 


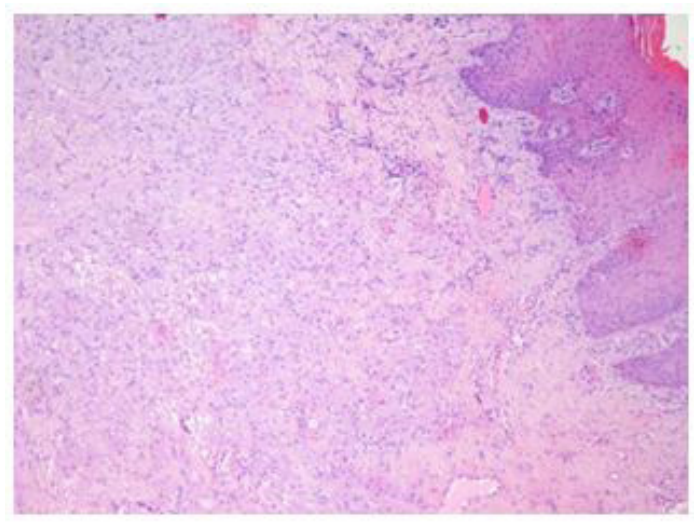

Figure 5: Granular cell tumor (round to polygonal cells, with eosinophilic granular cytoplasm and small nucleus). Hematoxylin and eosin stain. Magnification 40x

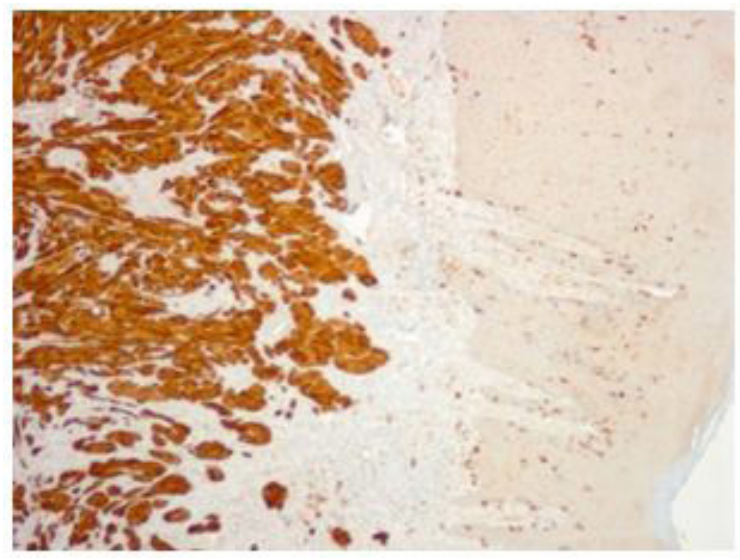

Figure 6: Immunohistochemical positivity with S-100 stain. Magnification 40x

\section{Discussion}

GCT is a slow growing solitary tumor and can be multiple in 5 to $16 \%$ of the cases [10]. 45\% to $65 \%$ of all GCTs are in the head and neck region and $70 \%$ of 52 these are found in the oral cavity (mainly in the tongue, oral mucosa and hard palate) [1]. Generally, it is an asymptomatic nodular lesion and a pinkish or yellowish surface $[1,11]$.

GCT is covered by intact mucosa, however bigger lesions may have an ulcerated surface and simulate a malignant tumor [1]. It is unencapsulated and has a poorly defined margin [1,11]. Imaging has a significant role in the diagnosis of soft tissue tumors of the head and neck. When there is an obvious or suspected head and neck tumor, Computed tomography (CT) is often the first diagnostic imaging examination performed [9]. Magnetic Resonance Imaging (MRI) has higher soft tissue resolution, allowingdifferentiation and characterization of soft tissue tumors [9]. Physiologic imaging techniques, such as PET/CT and diffusion-weighted MRI can help differentiating malignant and benign soft tissue tumors however, they aren't usually diagnostic [9].

However, TC and MRI have limitations [12]. Metal artifacts from dental alloysandimplants can interfere. Imagesfromsmalland superficial tonguelesionsaren't clearandinconclusive [12]. Consideringthis,small tongue masses are usually removed based on inspection and palpation [12].

Comparedto TC and MRI, intraoral ultrasonography of the tongue masses, complemented by Doppler, is suitable and can show the internal structure and vascularity of the masses, without metal artifacts [12]. The extraoral ultrasonography doesn't provide acceptable images of the tongue and palate [12].

Regarding our clinical cases, CT and MRI weren't performed because both lesions were superficial and small. Intraoral ultrasonography is not available in our hospital. So, surgical excision was mandatory as histopathology remains the gold standard for definitive diagnosis of soft tissue tumors and the excision of the entire lesions, with a safety margin, possible.

Most of the GCTs are benign, and only $1 \%$ to $2 \%$ have a malignant transformation, being reported in literature in less than 30 cases [11]. The most common metastasis sites are lymph nodes and lungs [13]. According to some authors, the GCT does not undergo malignant transformation but may coexist with carcinoma [3].

Fanburg-Smith and colleagues proposed six criteria for a histological diagnosis of malignancy: necrosis, spindle cells, and vesicular nuclei with large nucleoli, increased mitotic activity, increased nucleocytoplasmic ratio 63 and pleomorphism [3]. If three or more of these are present, the tumor is considered malignant [3]. 
Histologically, tumor cells consist of sheets and cords of polygonal or fusiform cells with small nuclei and abundant granular eosinophilic cytoplasm [1]. This granular appearance is due to the presence of large amounts of lysosomes [11]. Marked pseudoepitheliomatous hyperplasia can be seen and mimic a squamous cell carcinoma, so excision should be deep enough to include underlying infiltrating granular cells $[1,14]$.

Immunohistochemical studies suggest a neuroectodermal origin, supported by specific neuronal markers positivity, such as S100 protein and enolase [1]. Nowadays, it is accepted that tumor cells arise from Schwann cells or their precursors [1]. Differential diagnosis should include any intraoral soft tissue masses, such as fibroepithelial polyp, neurofibroma, dermoid cyst, minor salivary gland tumor, lipoma and others [6,14]. Surgical excision is the treatment of choice [3]. When tumor resection is complete, the recurrence rate is low (approximately 2 to $8 \%$ ) [1,15]. The lack of capsule, frequently, compromises the ability to obtain tumor-free margins (as observed in case 2), so excision should have wide margins [13]. Incomplete resection often results in local recurrence, with a $20 \%$ recurrence rate $[13,15]$.

\section{Conclusion}

Despite its low prevalence, GCT should be considered in the differential diagnosis of oral lesions, especially in the tongue. Histopathology is the gold standard for the diagnosis of GCT. The prognosis is good as less than $2 \%$ are malignant. However, when tumor excision is not complete, local recurrence is frequent. Adequate surgical margins are necessary as the tumor has no capsule and invades surrounding structures. Follow-up must be extended and regular to allow appropriate management in case of recurrence.

\section{References}

1. Nagaraj PB, Ongole R, Bhujanga-Rao BR (2006) Granular cell tumor ofthetongue in a 6-91year-old girl: A case report. Med Oral Patol Oral Cir Bucal 11: 162-4.

2. Machado I, Cruz J, Lavernia J, Llombart-Bosch A (2015) Solitary, multiple, benign, atypical, or malignant: the "Granular Cell Tumor" puzzle. VirchowsArchiv 468: 527-38.

3. Bitar M, Afif Al KA, Fatani MI (2011) Granular cell tumor: Case report. Journal of the Saudi Society of Dermatology \& Dermatologic Surgery 15: 25-7.

4. Ferraz EG, Couto AR, Provedel L, Sarmento VA, Reis SRA (2005) Granular cell tumor: report of two cases [Tumor de células granulares: relato de dois casos]. Rev Clín PesqOdontol 2: 45-151

5. Soares AB, Dipe LR, Furuse C, Araújo VC (2008) Granular cell tumor: case report in an unusual location [Tumor de células granulares: relato de caso em uma localização incomum] Rev Gaúch Odontol 56: 89-92

6. Curra M, Martins MD, Filho MSA, Martins MAT, Munerato MC (2011) Granular cell tumor: report of two cases [Tumor de células granulares: relato de dois casos]. RPG Rev Pós Grad 18: 266-8.

7. De Rezende L, Lucendo AJ, Álvarez-Argüelles H (2007) Granular cell tumors of the esophagus: report of five cases and review of diagnostic and therapeutic techniques. Dis of the Esophagus 20: 436-43.

8. Fletcher CDM, Bridge JA, Hogendoorn P, Mertens F (2013) WHO Classificationof Tumours of Soft Tissue and Bone (4 $4^{\text {th }}$ Edn) WHO, Switzerland.

9. Razek AA, Huang BY (2011) Soft Tissue Tumors of the Head and Neck: Imaging-based Review of the WHO Classification. Redio Graphics 3: 1923-54.

10. Hasanov A, Musayev J, Onal B, Rahimov C, Farzaliyev I (2011) Gingival granular cell tumor of the newborn: a case report and review of literature. Turk J Pathol 27: 161 .

11. Patti R, Almasio PL, DiVita G (2006) Granular cell tumor of stomach: A case report and review of literature. World J Gastroenterol 12: 3442-5.

12. Sugawara C, Takahashi A, Kawano F, Kudo, Ishimaru N, et al. (2016) Intraoral ultrasonography of tongue mass lesions. Dentomaxillofac Radiol 45: 20150362. 13. Aoyama K, Kamio T, Hirano A, Seshimo A, Kameoka S (2012) Granular cell tumors: a report of six cases. World J Surg Oncol 10: 204.

14. Barbieri M, Musizzano Y, Boggio M, Carcuscia C (2011) Granular celltumourofthetongue in a 14-year-old boy: case report. Acta Otorhinolaryngol Ital 3: 186-9. 15. Gupta R, Jain S,Goel G, Singh N (2013) Recurrentbenigncutaneous granular cell tumor: A case report. J Cytol 30: 287.

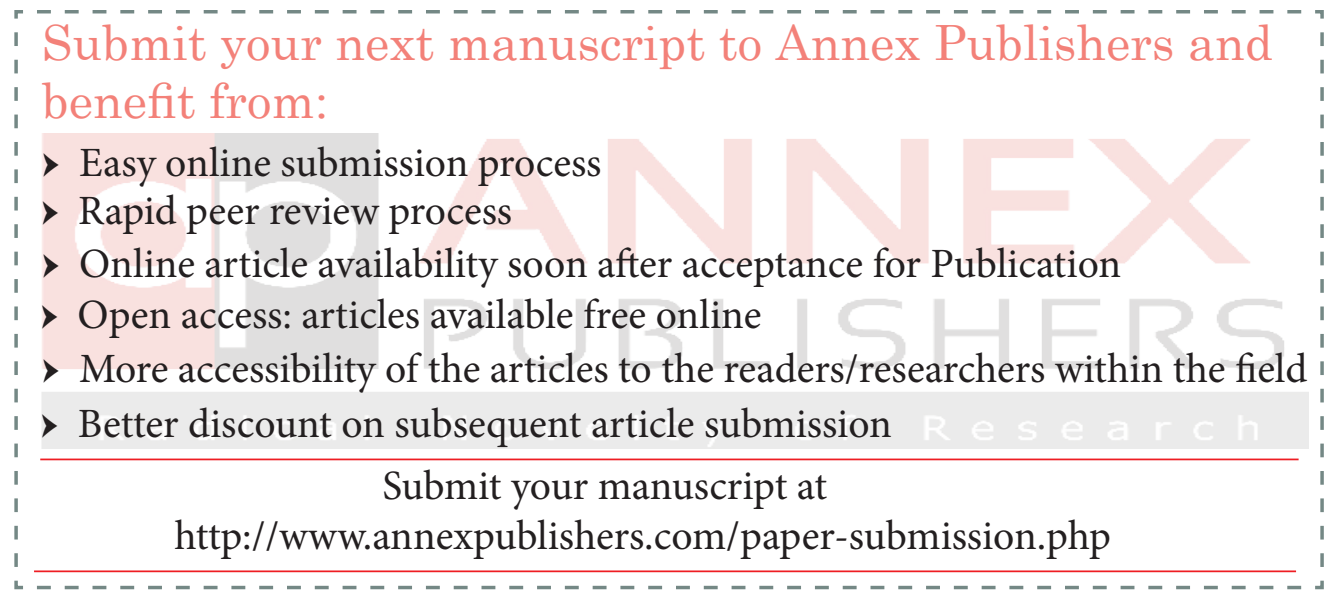

